\title{
A comparative study between mechanical and manual pollination in two premier Saudi Arabian date palm cultivars
}

\author{
N. A. Al-Wusaibai ${ }^{*}$, A. Ben Abdallah ${ }^{2}$, M. S. Al-Husainai ${ }^{1}$, H. Al-Salman ${ }^{1}$ and M. Elballaj ${ }^{2}$ \\ ${ }^{1}$ National Date Palm Research Centre - Al-Hassa - Saudi Arabia \\ ${ }^{2}$ FAO-Project (UTFN/SAU/015/SAU) \\ “N_alwusaibai@yahoo.com, ala200090@yahoo.fr, MS_alhusaini@hotmail.com, husian.mns@hotmail.com, \\ elbellajmounir@yahoo.fr
}

\begin{abstract}
The Kingdom of Saudi Arabia produces nearly a million tones of dates annually from an estimated 25 million palms. Date palm (Phoenix dactylifera L.) is a dioecious crop where male and female inflorescences are on separate palms. To ensure good fertilization and overcome disadvantages of dichogamy, enhance fruit set and sustain yield levels, each female inflorescence has to be artificially pollinated either manually which is time consuming and labour intensive or mechanically using pollinating devices. We therefore carried out a comparative study to assess the yield and yield attributes between manual and mechanical pollination in two premier date palm cultivars of Saudi Arabia viz. Khalas and Sheshi. Results indicate that manually pollinated palms gave the best fruit set in both the cultivars. However, with regard to yield results were cultivar specific. In Khalas, yield levels were statistically at par for both manual and mechanical pollination ranging from 10.99 to $11.54 \mathrm{Kg}$ per bunch, while mechanical pollination was significantly superior to manual pollination in the cultivar Sheshi, where pollen : flour ratio of 1:15 resulted in the best yield of 8.06 $\mathrm{Kg}$ per bunch.
\end{abstract}

Keywords: Date palm, Phoenix dactylifera, Dioecious, Mechanical pollination, Manual pollination, Pollen, Female inflorescences, Yields.

Introduction

Date palm (Phoenix dactylifera L.) is a major crop fruit crop in the Arabian Peninsula where it is closely associated with the life of the people since pre-historic times. Date palm is a multipurpose tree providing, fibre, carbohydrates, minerals and vitamins besides having certain medicinal properties (Mohamed, 2000; Vayalill, 2002; Al-Farsi et al., 2005; Ishurd \& Kennedy, 2005; Baloch et al., 2006; Al-Abdoulhadi et al., 2011a,b; ). The Kingdom of Saudi Arabia has an estimated 25 million date palms producing nearly a million tones of dates annually. More than 400 different date palm cultivars are reported to exist in Saudi Arabia (Anonymous, 2006).

With an estimated three million palms the Al-Hassa oasis in the Eastern Province is the largest in the Kingdom where Asif et al, 1986 grouped date palm cultivars based on the season of production. Khalas, a mid-season cultivar is widely cultivated in the Al-Hassa oasis and considered by many as the best date in the world, with mostly medium to big sized fruits that are consumed as both fresh (rutab) and dry (tamar) dates which store well. Currently the cultivar Khalas is cultivated in more than $60 \%$ of the area (Al -Khatib et al., 2006; Al-Mahla \& Hussein 2003). Sheshi is also an important date palm cultivar of the Al-Hassa oasis. Sheshi produces mostly medium to large fruits that are plump and firm in texture. Skin separation of fruits is common in this cultivar which often lowers the quality and value of the produce (Asif et al., 1986; Sakr et al, 2010; Al-Abbad et al, 2011).

Date palm is a dioecious crop where male (pollen bearing) and female (fruit bearing) inflorescences are on

Research article

CIndian Society for Education and Environment (iSee)

http://www.indjst.org separate palms. Unisexual flowers of date palm are either pistilate (female) or staminate (male) in character where the male palm produces pollen and female palm bears fruit (Popenoe, 1992; Zaid \& De Wet, 2002; Vijayalaxmi Kinhal \& Parthasarathy, 2008). To ensure good fertilization and overcome disadvantages of dichogamy and also reduce the number of male palms in the field, artificial pollination is carried out in commercial plantations, where pollen harvested from staminate flowers are used for artificial pollination which is done manually as traditionally taken up by date farmers throughout the Middle East or mechanically through pollen dusters.

Bonavia (1885) first attempted mechanical pollination of date palm in India. In USA ground-level dusters have been used to mechanically pollinate date palm since the late nineteen sixties (Brown \& Perkins, 1969; Brown et al., 1970; Perkins \& Burkner, 1973). Mechanical pollination in date palm has been investigated in the Middle East and is reported to have several advantages including high efficiency, decrease in pollen consumption, saving of time, less labour intensive etc. (Shabana et al., 1986; El-Kassas, 1986; El-Mardi et al., 2002; Hajian, 2005).

In commercial plantations the female flowers are usually pollinated by hand cutting the strands of male flowers and inserting them between female flower clusters during the first few days of its opening when the female flowers are receptive (Sawaya, 1986). This ensures good fertilization and overcomes disadvantages of dichogamy besides enhancing fruit set and sustaining yield levels. Manual pollination is time consuming and Indian J.Sci.Technol. 
also a labour intensive operation. Efficiency of pollen has been reported to be enhanced by mixing date palm pollen with wheat flour or a solution of $10 \%$ sucrose (Carpenter, 1981). Mechanical pollination of palms using ground level pollen dusters has been reported since the late nineteen sixties (Brown \& Perkins, 1969; Nixon \& Carpenter, 1978). Mechanical pollen dusters with lances of different lengths are now

available that facilitate pollination in date palm at higher levels. We therefore carried out a comparative study to assess the yield and yield attributes between manual and mechanical pollination in two premier date palm cultivars of Saudi Arabia viz. Khalas and Sheshi.

\section{Materials and methods}

The study was carried out during the following seasons: 2008, 2009 and 2010 at the experimental site of the National Date Palm Research Center (NDPRC) at Al Hassa, Saudi Arabia. Al-Hassa (25 ${ }^{\circ} 19^{\prime} 60^{\prime \prime} \mathrm{N}$ latitude and $49^{\circ} 37^{\prime} 60^{\prime \prime} \mathrm{E}$ longititude) is the largest date palm oasis of Saudi Arabia situated in the Eastern Province of the Kingdom having an estimated three million date palms.

Staminate inflorescences were harvested from a single male palm in the date plantation at NDPRC, AlHassa which were transferred to the laboratory and air dried for 24-48 hours. These staminate inflorescences were then put in a bag and pollen was extracted manually. Part of the pollen was set aside for taking up pollination mechanically where in the extracted pollen was mixed with flour in pollen: flour ratio of 1:5(I), 1:10(II) and 1:15(III). The fourth treatment of manual pollination served as a control. The three mechanical pollination treatments and one manual pollination treatment were taken up in Khalas and Sheshi date palm cultivars planted at NDPRC. Pollination was carried in the above cultivars from 3-5 days of opening of the female inflorescences. Mechanical pollination was done using a portable pollen duster which had a $10 \mathrm{~m}$ long telescopic tube that carried the pollen to the crown of the palm and dusted the pollen on the selected female inflorescences, while manual pollination was carried out as per the traditional practice by inserting 5 strands of the male inflorescence in the female inflorescence. Each of the four treatments was replicated thrice. In all there were 12 treated female inflorescences per palm.

All treated inflorescence were covered with craft paper to avoid contamination of the treated inflorescences by other pollen. The cover was removed after five weeks and fruit set rate was determined in five randomly selected strands per treated bunch. Subsequently, each bunch was inserted into a plastic mesh were fruits that dropped got collected. At fruit maturity the bunch weight per treatment was recorded. Further, the physical characteristics of the treated dates (fruit length and breadth) were noted besides recording the fruit drop per treated bunch at fortnightly intervals. The experiment was carried out using the completely randomized block design and data was subjected to ANOVA where treatment means were differentiated at $p=0.05$. The results are presented and discussed below.

\section{Results and discussion}

Fig. 1. Effect of type of pollination on fruit set in Khalas and Sheshi cultivars of date palm

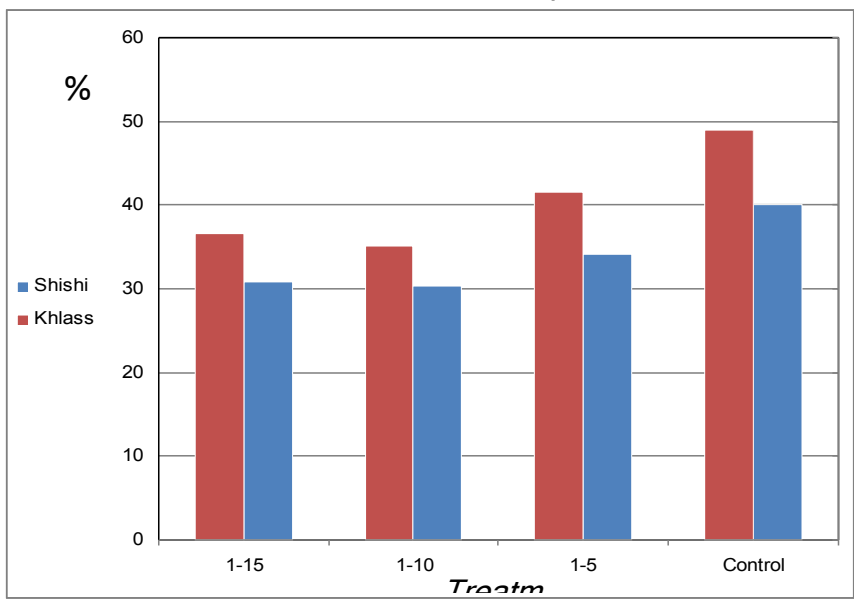

From Fig. 1 it is evident that manual pollination resulted in better fruit set as compared to the mechanically pollinated bunches in both Khalas and Sheshi cultivars. In bunches that were mechanically pollinated the best fruit set was obtained when pollen: flour ratio of 1:5 was maintained. Attalla et al. 1998 reported that dusting the spathe with 5,10 or $15 \%$ pollen powder significantly increased the fruit set in the cultivars Sukari and Helwa Qassim, while El-Mardi et al. (2002) reported that motorized duster produced lower fruit set that hand duster. El-Kassas (1986) recorded no significant differences in fruit set and yield either by mechanical or manual pollination methods.

With regard to fruit length mechanically pollinated Khalas palms produced significantly longer fruits $(32.07 \mathrm{~mm})$ when a pollen: flour ratio of $1: 15$ was used which was superior to the other mechanical pollination treatments and also the manually pollinated bunches.

Table 1. Effect of pollination on the length and breadth of dates

\begin{tabular}{|l|l|l|l|}
\hline Cultivar & \multicolumn{1}{|c|}{$\begin{array}{c}\text { Pollination } \\
\text { type }\end{array}$} & $\begin{array}{c}\text { Fruit length } \\
(\mathrm{mm})\end{array}$ & $\begin{array}{c}\text { Fruit breadth } \\
(\mathrm{mm})\end{array}$ \\
\hline Khalas & Mechanical & & \\
\hline & I & $30.64 \mathrm{~b}$ & $18.92 \mathrm{a}$ \\
\hline & II & $30.94 \mathrm{~b}$ & $19.32 \mathrm{a}$ \\
\hline & III & $32.07 \mathrm{a}$ & $19.48 \mathrm{a}$ \\
\hline & Manual & $31.16 \mathrm{~b}$ & $19.10 \mathrm{a}$ \\
\hline Sheshi & Mechanical & & \\
\hline & I & $29.95 \mathrm{~b}$ & $19.50 \mathrm{~b}$ \\
\hline & II & $31.27 \mathrm{ab}$ & $20.04 \mathrm{~b}$ \\
\hline & III & $29.78 \mathrm{~b}$ & $18.20 \mathrm{c}$ \\
\hline & Manual & $32.00 \mathrm{a}$ & $21.36 \mathrm{a}$ \\
\hline
\end{tabular}

- Pollen: Flour ratio (I- 1:5, II - 1:10, III - 1:15).

- Figures followed by the same letter are not significantly different $(p=0.05)$. 
With regard to the cultivar Sheshi manual pollination resulted in production of significantly longer fruits $(32.00 \mathrm{~mm})$. Further, type of pollination did not influence fruit breath in the cultivar Khalas while in the cultivar Sheshi significantly superior fruit breadth $(21.36 \mathrm{~mm})$ was obtained in bunches that were manually pollinated (Table 1).

Table 2. Effect of pollination on drop of mature dates (Tamar stage) in date palm cultivars

\begin{tabular}{|l|c|c|c|c|}
\hline \multirow{3}{*}{ Cultivar } & \multicolumn{4}{c|}{ \#Mean fruit drop per bunch } \\
\cline { 2 - 4 } & \multicolumn{2}{|c|}{ Mechanical pollination } & \multirow{2}{*}{$\begin{array}{c}\text { Manual } \\
\text { pollination }\end{array}$} \\
\cline { 2 - 4 } & I & II & III & po.70a \\
\hline Khalas & 39.10 & 40.80 & 44.50 & $30.70 \mathrm{a}$ \\
\hline Sheshi & 40.10 & 31.80 & 43.20 & $28.10 \mathrm{a}$ \\
\hline
\end{tabular}

${ }^{*}$ Pollen: Flour ratio (I - 1:5, II - 1:10, III - 1:15).

\# Treatment means are statistically not significantly different $(p=0.05)$

From Table 2 it is evident that pollination type did not significantly influence fruit drop in both Khalas and Sheshi. However, in both the cultivars least fruit drop was noticed in manually pollinated bunches (Table 2). Although treatment means with regard to yield (Table 3) in the cultivar Khalas were similar for both the methods of pollination, the best yield was recorded in manually pollinated bunches (11.54 kg/ bunch). El- Mardi et al. (2002) reported no significant effect of pollination method on yield while, Haffar et al. (1997) reported that mechanical pollination had a significant influence on fruit yield and quality in the cultivar Khalas. In the cultivar Sheshi mechanical pollination was significantly superior to manual pollination with pollen: flour ratio of 1:15 giving the best yield $(8.06 \mathrm{Kg} /$ bunch). El-Kassas \& Mahmoud, 1986 compared mechanical pollination to hand pollination in date palm and found that the former gave good results in terms of yield besides reducing labour to an extent of $50 \%$ as compared to manual pollination. Reports from Egypt suggest that delaying pollination beyond the seventh day of spathe cracking resulted in significant reduction in initial fruit set and bunch weight (El-Salhy et al., 2011).

Table 3. Effect of pollination on the yield of date palm cultivars

\begin{tabular}{|l|c|c|c|l|}
\hline \multirow{2}{*}{ Cultivar } & \multicolumn{4}{|c|}{ Yield ( Kg per bunch) } \\
\cline { 2 - 4 } & \multicolumn{3}{|c|}{ Mechanical Pollination* } & \multicolumn{1}{c|}{$\begin{array}{c}\text { Manual } \\
\text { pollination }\end{array}$} \\
\cline { 2 - 5 } & $\mathrm{I}$ & $\mathrm{II}$ & $\mathrm{II}$ & $11.54 \mathrm{a}$ \\
\hline Khalas & $10.99 \mathrm{a}$ & $11.32 \mathrm{a}$ & $11.31 \mathrm{a}$ & $6.3 \mathrm{~b}$ \\
\hline Sheshi & $7.04 \mathrm{ab}$ & $7.84 \mathrm{ab}$ & $8.06 \mathrm{a}$ & \\
\hline
\end{tabular}

*Pollen: Flour ratio (I - 1:5, II - 1:10, III - 1:15). Figures

followed by the same letter are not significantly different $(p=0.05)$

Conclusion

In view of our findings and previous reports on the subject we propose that mechanical pollination of date palm may be encouraged in the region in view of its efficiency, increasing labour cost associated with manual pollination which is time consuming that results in enhanced cost of production.

\section{Acknowledgement}

The authors thank the Ministry of Agriculture, Kingdom of Saudi Arabia for providing the necessary facilities to Research article CIndian Society for Education and Environment (iSee) conduct this trial at the National Date Palm Research Centre (NDPRC), Al-Hassa, through the FAO funded project UTFN/SAU/015/SAU. We also wish to thank Mr.Adnan Al-Afaleq, General Director (NDPRC) and Mr.Ali AlJabr, Research Director (NDPRC) for their support in carrying out the study.

\section{References}

1. Al-Abbad A, Al-Jamal M, Al-Elaiw Z, Al-Shreed F and Belaifa $H$ ( 2011) A study on the economic feasibility of date palm cultivation in the Al-Hassa oasis of Saudi Arabia. J.Dev. \& Agri. Eco. 3(39), 463-468.

2. Al-Abdoulhadi IA, Al-Ali S, Khurshid K, Al-Shryda F, Al-Jabr AM and Ben Abdallah A (2011a) Assessing fruit characteristics to standardize quality norms in date cultivars of Saudi Arabia. Indian J.Sci. Technol. 4 (10),1262-1266. Domain site: http://www.indjst.org.

3. Al-Abdoulhadi IA, Dinar HA, Ebert $G$ and Büttner $C$ (2011b) Effect of salinity on leaf growth, leaf injury and biomass production in date palm (Phoenix dactylifera L.) cultivars. Indian J.Sci.Technol. 4 (11), 1542-1546. Domain site: http://www.indjst.org.

4. Al-Farsi $M$, Alasalvar $C$, Morris $A$, Barron $M$ and Shahidi F (2005) Compositional and sensory characteristics of three native sun-dried date (Phoenix dactylifera L) varieties grown in Oman. J. Agri \& Food Chem., 53, 7586-7591.

5. Al-Khatib AA, Al-Jaber MA and Al-Jabber A (2006) Date palm in the Kingdom of Saudi Arabia (National Agriculture Development Company (NADEC), Saudi Arabia. pp:136.

6. Al-Malha $\mathrm{J}$ and Husseini AA (2003) Cost of cultivation of Khalas dates in the Al- Hassa oasis. King Saud University, Riyadh, Saudi Arabia. pp;843-853.

7. Anonymous (2006) The famous date varieties in the Kingdom of Saudi Arabia (Ed. Ministry of Agriculture, Kingdom of Saudi Arabia and Food and Agriculture Organization of the United Nations). pp: 245.

8. Asif MI, Al-Ghamdi AS, Al-Tahir OA and Latif RAA (1986) Studies on the date palm cultivars of Al-Hassa oasis. In, proceedings of the second symposium on date palm in Saudi Arabia. King Faisal University, Al Hassa Saudi Arabia, 405-413.

9. Attalla AM, Warring MO and Sharaan FA (1998) Suitable time of pollination of two Saudi Arabian date palm cultivars. Alexendria J. Agri. Res. 43 (3), 203208.

10.Baloch MK, Saleem SA, Ahmad K, Baloch AK and Baloch WA (2006) Impact of controlled atmosphere on the stability of Dhakki dates. Swiss Society of Food Sci. \& Tech., 39, 671-676.

11.Bonavia E (1885) The future of date palm in India. Thacker, Calcutta. pp: 188.

12.Brown GK and Perkins RM (1969) Pollen application to date palms in California. Proceedings of the 4th International Agricultural Aviation Congress, Kingston, Ontario, Canada, pp: 540-547. 
13.Brown GK, Perkins RM, and Vis EG (1970) Mechanical pollination experiments with the degelet noor date palm in 1969. Date Growers Institute Report 47, 19-24.

14. Carpenter JB (1981) Improvement of traditional date culture. The Date Palm J. 1(1), 1-17.

15.El-Kassas SE (1986) Manual bunch and chemical thinning of Zaghloul dates. Proc. of the 2nd Symposium on the Date Palm. King Faisal University, Al-Hassa, Saudi Arabia, pp: 187-196.

16. El-Kassas SE and Mahmoud HM (1986) The possibility ofpollinating date palm by diluted pollen. Proc. $2^{\text {nd }}$ Symp. Date Palm. King Faisal University, AlHassa, Saudi Arabia, pp: 317-321.

17.El-Mardi MO, Esechie $\mathrm{H}$, Al-Kharousi $\mathrm{LM}$ and Abdelbasit KM (2002) Effect of pollination method on changes in physical and chemical characteristicsof date Fruit during development. Sultan Qaboos University. J. Sci. Res. Agri. Sci., 7(1), 21-27.

18. El-Salhy A, Abdel- Galil HA, El- Akkad M M and Diyab, YM (2011) Effect of delaying pollination on yield and fruit quality of Sewy date palm under new valley conditions in Egypt. Res.J. Agri \& Bio. Sci., 7(6), 408412.

19. Haffar IH, Al-Jubri and Ahmed MH (1997) Effect of pollination frequency and pollen concentration on yield and fruit characteristics of mechanically pollinated date palm tree (Phoenix dactylifera L.) var Khalas. J. Agri. Engg. Res., 68(1), 11-14.

20. Hajian S (2005) Fundamentals of pollination in date palm plantations in Iran. Proc.Internat. conf. on mango $\&$ date palm., Culture and Export. 20-23, Faislabad, Pakistan.

21.Ishurd $O$ and Kennedy JF (2005) The anti-cancer activity of polysaccharide prepared from Libyan dates (Phoenix dactylifera L). Carbohydrate Polymers. 59, 531-535.

22. Mohamed AE (2000) Trace element levels in some kinds of dates. Food Chemistry, 49, 107-113.

23.Nixon RW and Carpenter JB (1978) Growing dates in the United States. USDA publication, Washinghton DC. pp: 62.

24.Perkins RM and Burkner PF (1973) Mechanical pollination of datepalms. Date Growers Institute Report, 50, 4-7.

25.Popenoe $P$ (1992) The pollination of the date palm. J. American Oriental Society, 42, 343-354.

26.Sakr MM, Abu Zeid IM, Hassan AE, Baz A-G.IO and Hassan WM (2010) Identification of some date palm (Phoenix dactylifera) cultivars by fruit characters. Indian J.Sci.Technol. 3 (3), 338-343. Domain site: http://www.indjst.org.

27.Sawaya WN (1986) Chapter I: Overview -Dates of Saudi Arabia (pp: 1- 44) In Dates of Saudi Arabia. W. N. Sawaya (ed.).pp:200.
28.Shabana RH, Mawlood EA, Khalil, T and Ghalib HA (1986) Mechanical pollen extraction and pollination. $J$. Agri. Water Resource. 5, 227-240.

29.Vayalill PK (2002) Antioxidant and antimutagenic properties of aqueous extract of date fruit (Phoenix dactylifera L. Arecaceae). J. Agri \& Food Chem. 50,610-617.

30.Vijayalaxmi Kinhal and Parthasarathy N (2008) Ecology of a dioecious palm Phoenix pusilla (Arecaceae), endemic to Coromandel coast of India.Indian J.Sci.Technol. 1 (3), 1-7. Domain site: http://www.indjst.org.

31.Zaid A and De Wet PF (2002) Pollination and Bunch Management (Chap. VIII, pp: 145-175). In: Date palm cultivation. A Zaid (Ed.). FAO plant production and protection paper 156, Review 1. (Available on http://www.fao.org/DOCREP/006/Y4360E/y4360e0g.h tm\#bm16). 